\title{
SURGING VERSUS CONTINUOUS TURBIDITY CURRENTS: FLOW DYNAMICS AND DEPOSITS IN AN EXPERIMENTAL INTRASLOPE MINIBASIN
}

\author{
MICHAEL P. LAMB, ${ }^{1 *}$ THOMAS HICKSON,${ }^{2}$ JEFFREY G. MARR,${ }^{1}$ BEN SHEETS,${ }^{1}$ CHRIS PAOLA,${ }^{1}$ AND GARY PARKER ${ }^{1}$ \\ ${ }^{1}$ St. Anthony Falls Laboratory, University of Minnesota, Minneapolis, Minnesota 55414, U.S.A. \\ email: mike@ocean.washington.edu \\ ${ }^{2}$ Department of Geology, University of St. Thomas, 2115 Summit Avenue, OWS 153, St. Paul, Minnesota 55105, U.S.A.
}

\begin{abstract}
Small intraslope basins ( $\left.100 \mathrm{~km}^{2}\right)$, or "minibasins," such as those found on the continental slope of the Gulf of Mexico, have been filled predominantly by turbidity currents. Each minibasin is the result of local subsidence and is partially or completely isolated from neighboring basins by ridges formed from compensational uplift. We undertook a series of experiments to investigate the relationship between the flow dynamics of turbidity currents entering a minibasin and the stratal architecture of their deposits. The experiments were performed using continuous-feed turbidity currents and surge-feed turbidity currents. A dimensionless ponding number is developed to compare the geometry of the deposits with the dynamics of the flows that filled the basins. The experimental surging turbidity currents created a deposit that was notably more ponded than the deposits of continuous turbidity currents.
\end{abstract}

\section{INTRODUCTION}

Intraslope salt-withdrawal basins, or "minibasins," are an important feature of the northwestern continental slope of the Gulf of Mexico (Pratson and Ryan 1994). Similar basins have been encountered in both modern and ancient sedimentary successions throughout the world (e.g., Trinidad and Tobago, Brami et al. 2000; Angola, Schollnberger and Vail 1999). Minibasins are formed from diapirism due to the buoyant instability of a mobile substrate (e.g., salt body) overlain by a load of denser sediment. These basins typically have several hundred meters of relief and span areas on the order of $10^{1}-10^{2}$ square kilometers. An example of a seismic section from such a basin is shown in Figure 1. Depositional turbidity currents appear to have completely or partially filled many of the minibasins in the Gulf of Mexico. Many, but not all, of these minibasins are connected by submarine channels that form a drainage network that eventually discharges onto the abyssal plain of the Gulf of Mexico (Liu and Bryant 2000).

Turbidity currents are believed to have filled many minibasins and eroded channels into neighboring ridges through a process known as "fill and spill', (e.g., Winker 1996; Beauboeuf and Friedman 2000), creating sandrich deposits within minibasins that constitute prime targets for oil exploration. We undertook a series of experiments to investigate fill-and-spill processes by analyzing the relationship between the dynamics of the turbidity currents entering a minibasin and the stratal architecture of their associated deposits. We focused on two possibilities. Firstly, we considered large, continuous turbidity currents that traverse multiple neighboring basins, "filling and spilling" from basin to basin across several ridges, or through partially excavated canyons between ridges, in a single flow event. In this case, ridge incision and basin filling would occur during the same time interval for several successive basins and ridges. Secondly, we examined small, pulse-like flows that fill one basin at a time. These flows are unable to travel over the downstream lip of the basin until the basin is substantially filled with sediment. Once the basin is filled, successive turbidity current pulses may downcut the ridge and begin filling the next minibasin downstream.

\footnotetext{
* Present Address: School of Oceanography, University of Washington, Seattle, Washington 98195, U.S.A.
}

\section{EXPERIMENTAL APPROACH}

The experiments reported here represent an extension of an initial effort by Hickson et al. (2000). We used a flume at St. Anthony Falls Laboratory, University of Minnesota, specifically designed for the study of both surging and continuous turbidity currents. The tank is $0.31 \mathrm{~m}$ wide, $10.6 \mathrm{~m}$ long and $0.76 \mathrm{~m}$ deep. A model minibasin was installed in the flume (Fig. 2). The installed minibasin floor had a length of $4.1 \mathrm{~m}$ and a maximum relief of $0.15 \mathrm{~m}$. The dimensions of the experimental minibasin were constrained by the average dimensionless length-to-depth profiles and the average ratios of basin area to basin capacity $(\approx 9)$ of thirteen minibasins from the Gulf of Mexico, as determined from full-resolution multibeam data from the National Geophysical Data Center (Divins 2001). Here, basin capacity is defined as the maximum volume of fluid a basin can hold before spilling over its downstream lip.

The flume was equipped with a mixing tank and a damping tank (Fig. 2). The mixing tank was filled with a slurry of sediment and water, which was continuously circulated up to a constant head tank and back down to the mixing tank. During an experiment a portion of the slurry was diverted from the head tank into the flume (Fig. 3A). The slurry entered the minibasin flume through a headgate that restricted the flow thickness to $3 \mathrm{~cm}$. Whenever the turbidity current overflowed the minibasin, it emptied into the damping tank, which was drained from the bottom. The water level in the damping tank and flume was held constant by a fresh water supply at the top of the damping tank. In addition to keeping the ambient water in the flume above the turbidity current free of sediment, the damping tank served to entirely suppress reflection waves, which would have resulted had the turbidity current collided with a closed barrier at the downstream end of the flume. It should be pointed out, however, that turbidity currents could and did fully or partially reflect from the downstream lip of the minibasin itself, a feature that was intentionally designed into the experiments.

We performed four continuous-feed turbidity current experiments (c1c4) and one surge-feed turbidity current experiment consisting of twelve successive surges (s1-s12) and analyzed their resultant deposits. The input flow rates and the slurry compositions are summarized in Table 1 . All of the turbidity currents had an initial sediment concentration of $5 \%$ by volume, with the remainder being tap water. The sediment used in all experiments was composed of 50\% kaolinite clay and 50\% silica silt. At the small scale of the experiments reported here, silt tended to deposit out easily, with little or no resuspension. The suspended clay acted as an extra "driver" for the turbidity current, maintaining its density excess above clear water even as the silt settled out (Salaheldin et al. 2000).

For the first three continuous-feed experiments (c1, c2, c3) the sediment consisted of $50 \%$ kaolinite clay and $50 \%$ poorly sorted $20 \mu \mathrm{m}$ silt (silica flour). The sediment used in the fourth experiment (c4) consisted of 50\% kaolinite clay and $50 \%$ poorly sorted $45 \mu \mathrm{m}$ silt (silica flour). Input flow rates and concentrations were held constant throughout the runs, which ranged from 14 minutes to 55 minutes in duration. The bed deposit was profiled with a point gauge at the end of each run.

The surge-feed experiment consisted of twelve pulsed turbidity currents (s1-s12), the deposits of which were allowed to stack on top of one another. The sediment mix was $50 \%$ kaolinite clay and $50 \%$ poorly sorted $20 \mu \mathrm{m}$ silt, which is the same mix used in the first three continuous-turbidity- 


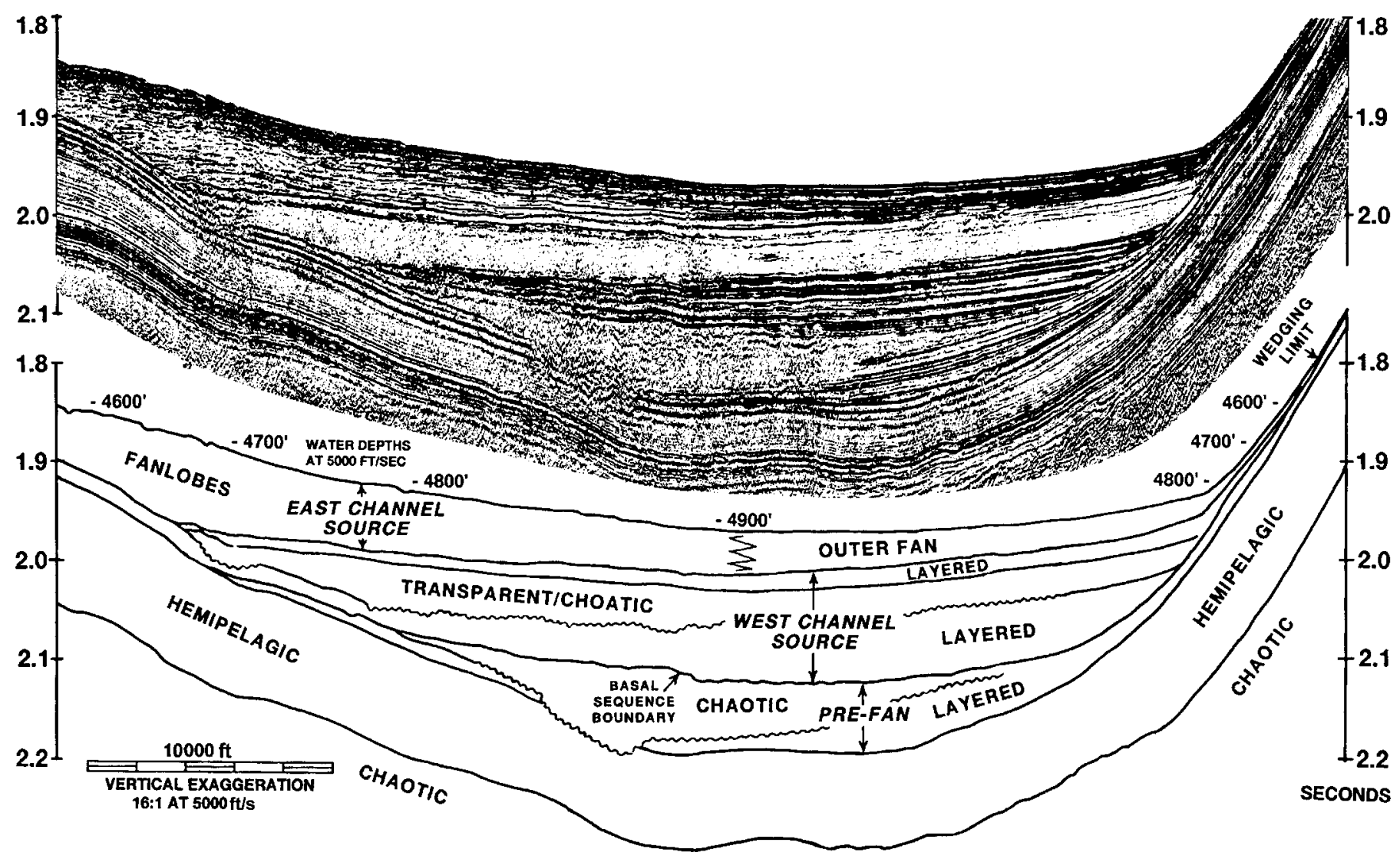

FIG. 1.-High-resolution seismic dip profile of a salt-withdrawal minibasin on the northern continental slope of the Gulf of Mexico, showing differentiation of major seismic facies. Diagram courtesy of Winker (1996).

current experiments. For each surge, the input flow rate was held constant at $1 \mathrm{l} / \mathrm{s}$ for a duration of $15 \mathrm{~s}$. The sizes of the surges were designed such that they resulted in little to no basin spillover. This corresponded to a surge volume that was 15 liters, or approximately $10 \%$ of the basin capacity. The capacity of the experimental minibasin was 141 liters with no sediment in the basin. The time between surges was on the order of 8 hours, a value chosen to allow for nearly complete settling of sediment. At the end of each surge, ultrasonic sonar was used to record the elevation of the sediment bed.

\section{RESULTS}

A dimensionless deposit ponding index number $(\mathrm{Po})$ is used to describe the experimental deposits:

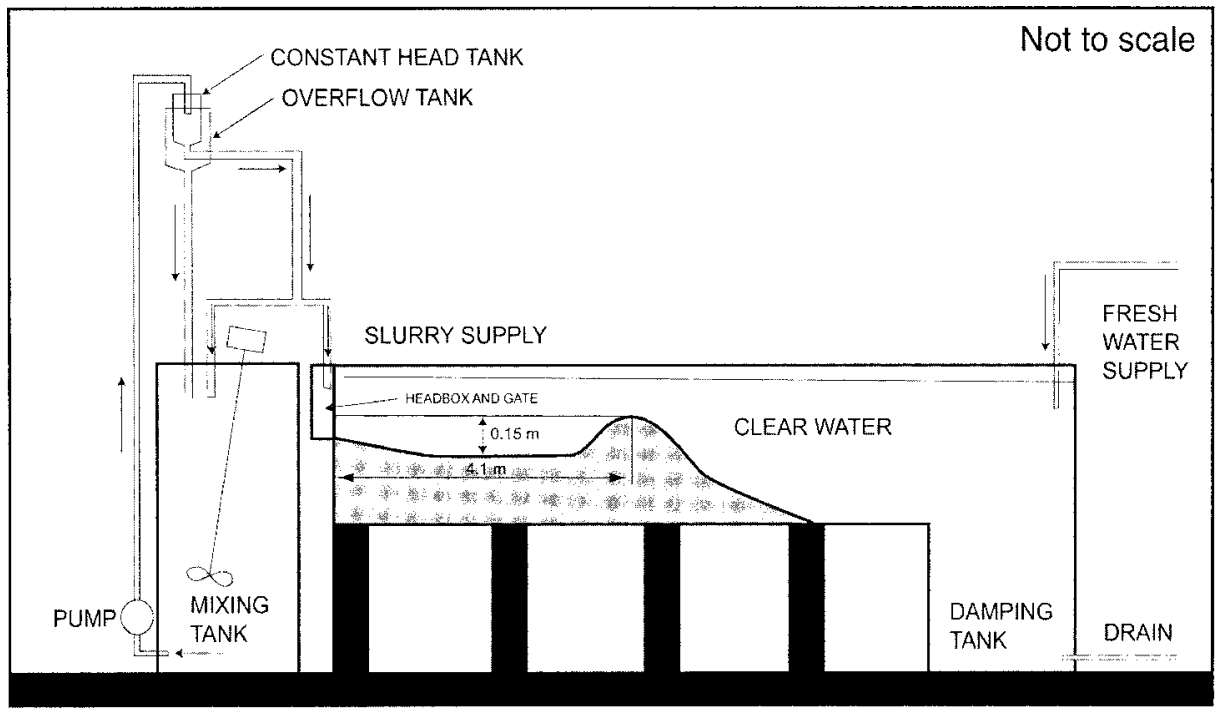

FIG. 2.-Schematic of the experimental flume. The slurry was kept in suspension in the mixing tank and pumped to a constant-head tank in order to maintain a steady sediment and slurry discharge in the flume. Any slurry that reached the end of the flume was vented out of the system from a bottom drain in the damping tank. The damping tank also suppressed any reflectional waves from the downstream end of the flume. 


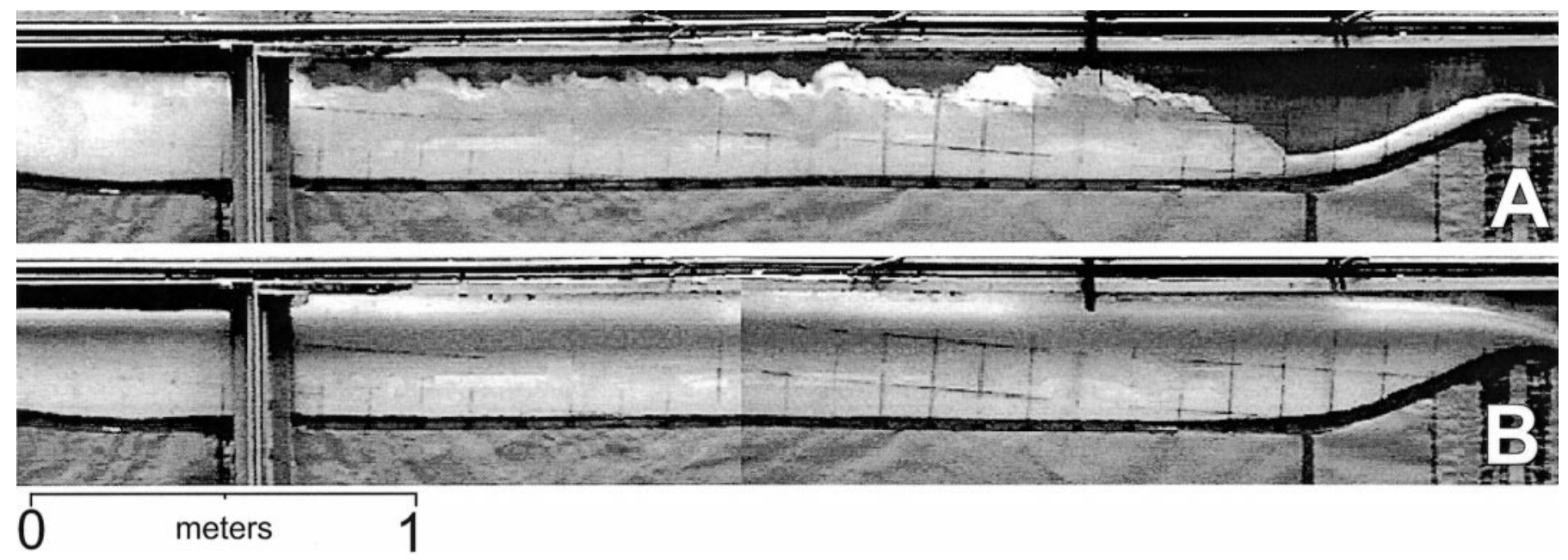

Fig. 3.-Photographs showing A) the head of a continuous-feed turbidity current entering the basin and $\mathbf{B}$ ) the same flow after setup of a quasi-steady dammed turbidity current. The flow was from left to right. The internal hydraulic jump is not shown in the image.

$$
\mathrm{Po}=-\frac{1}{L} \int_{0}^{L} \frac{d \theta}{d \eta} d x
$$

where $x$ is the downdip coordinate, $L$ denotes the streamwise length of the basin, $\theta(x)$ denotes the thickness of the deposit and $\eta(x)$ denotes the elevation of the initial bed. A deposit ponding index equal to one represents a completely ponded deposit (Fig. 4A), a deposit ponding index greater than unity represents a mounded deposit (Fig. 4B), and a deposit ponding index equal to zero represents a purely draped deposit (Fig. 4C). A deposit with accentuated highs, meaning that the flow deposits preferentially on the slopes rather than the center of the basin, would have a negative deposit ponding index (Fig. 4D).

\section{Continuous Turbidity Currents}

The flows for all four continuous-turbidity-current experiments were strongly influenced by the minibasin topography. The head of a continuous turbidity current traversed the basin and collided with the minibasin lip, such that part of the head overflowed the basin and the rest formed a backward-migrating bore (Fig. 5). The portion of the head that overflowed the basin resembled a surge-feed turbidity current filling the next downstream basin, even though its source was from a continuous flow. As shown in Figure 5, the bore eventually either stabilized at a point toward the

TABLE 1.-Input parameters (sediment concentration, discharge, velocity, and densimetric Froude Number) as well as the deposit ponding index and trapping effciency of the deposits from the four continuous flows (cl-c4) and the cumulative surge deposit (s1-s12).

\begin{tabular}{|c|c|c|c|c|c|}
\hline Experiment & $\mathrm{cl}$ & c2 & c3 & c4 & s1-s12 \\
\hline $\begin{array}{l}\text { Input flow rate } \\
\text { (liters/second) }\end{array}$ & 0.5 & 0.85 & 2 & 1 & 1 \\
\hline $\begin{array}{l}\text { Sediment concentration } \\
\text { by volume }\end{array}$ & 0.05 & 0.05 & 0.05 & 0.05 & 0.05 \\
\hline $\begin{array}{l}\text { Kaolinite concentration } \\
\text { by volume }\end{array}$ & 0.025 & 0.025 & 0.025 & 0.025 & 0.025 \\
\hline $\begin{array}{l}\text { Silt concentration } \\
\text { by volume }\end{array}$ & 0.025 & 0.025 & 0.025 & 0.025 & 0.025 \\
\hline Input velocity $(\mathrm{cm} / \mathrm{s})$ & 5.4 & 9.1 & 21.5 & 10.8 & 10.8 \\
\hline Approximate input $\mathrm{Fr}_{\mathrm{d}}$ & 0.35 & 0.59 & 1.38 & 0.69 & 0.69 \\
\hline $\begin{array}{l}\text { Mean silt grain size } \\
\text { (microns) }\end{array}$ & 20 & 20 & 20 & 45 & 20 \\
\hline Duration (seconds) & 3300 & 1860 & 840 & 1680 & 15 per surge \\
\hline Ponding index (Po) & 0.37 & 0.16 & 0.22 & 0.11 & 0.54 \\
\hline Trapping efficiency & 0.15 & 0.17 & 0.14 & 0.32 & 0.99 \\
\hline
\end{tabular}

upstream end of the basin, forming a well-defined internal hydraulic jump (experiment $\mathrm{c} 3$ ), or drowned out the entrance headgate (experiments $\mathrm{c} 1$, c2, and c4). The position of the bore and the basin overflow stabilized within about 60-80 seconds, after which setup of the continuous flow was complete and the flow changed only in response to the changing bed topography as sediment was deposited.

García and Parker (1989) and García (1993) have emphasized the role of internal hydraulic jumps in regard to turbidity current dynamics. A hydraulic jump is a shock by which a shallow, swift flow, i.e., a supercritical flow in terms of bulk densimetric Froude number, is converted to a deep, slow, subcritical flow. The bulk densimetric Froude number $\left(\mathrm{Fr}_{\mathrm{d}}\right)$ can be defined as follows:

$$
\mathrm{Fr}_{\mathrm{d}}=\frac{U}{\sqrt{\operatorname{RgCH}}}
$$

where $H$ denotes turbidity current layer thickness, $U$ denotes layer-averaged flow velocity, $C$ denotes layer-averaged volume sediment concentration in the turbidity current, $g$ denotes the acceleration of gravity, and $R$ denotes the submerged specific gravity of the sediment, which was about 1.65 for the sediment used in the present study. $\mathrm{Fr}_{\mathrm{d}}$ is greater than unity for a supercritical flow, and $\mathrm{Fr}_{\mathrm{d}}$ is less than unity for a subcritical flow. At an internal hydraulic jump, the bulk densimetric Froude number undergoes a rapid change from a value in excess of unity to a value below unity over a short distance.

Values of $\mathrm{Fr}_{\mathrm{d}}$ at the headgate for all experiments are reported in Table 1. In experiment $\mathrm{c} 3$, the turbidity current was supercritical as it entered the flume. The downstream lip of the minibasin acted to dam the flow, forcing a transition to subcritical flow via an internal hydraulic jump, so that the flow upstream of the hydraulic jump was supercritical and the flow downstream of the jump but within the basin was highly subcritical (Fig. 5). This would likely be the case for minibasins in nature. This is because turbidity currents, and indeed all dense bottom currents, can be expected to attain a densimetric Froude number of unity because of hydraulic control as they pass over a bed-elevation maximum and drain into a deep basin (e.g., Turner 1973). Thus, natural turbidity currents can be expected to make a transition from subcritical to supercritical flow as they pass over a minibasin lip. In addition, if a continuous supercritical flow enters a confined basin, the confinement sets up a hydraulic jump. In the cases of experiments $\mathrm{c} 1, \mathrm{c} 2$, and $\mathrm{c} 4$ the incoming flow was subcritical, so that the bore migrated upstream to the headgate before stabilizing, creating a 

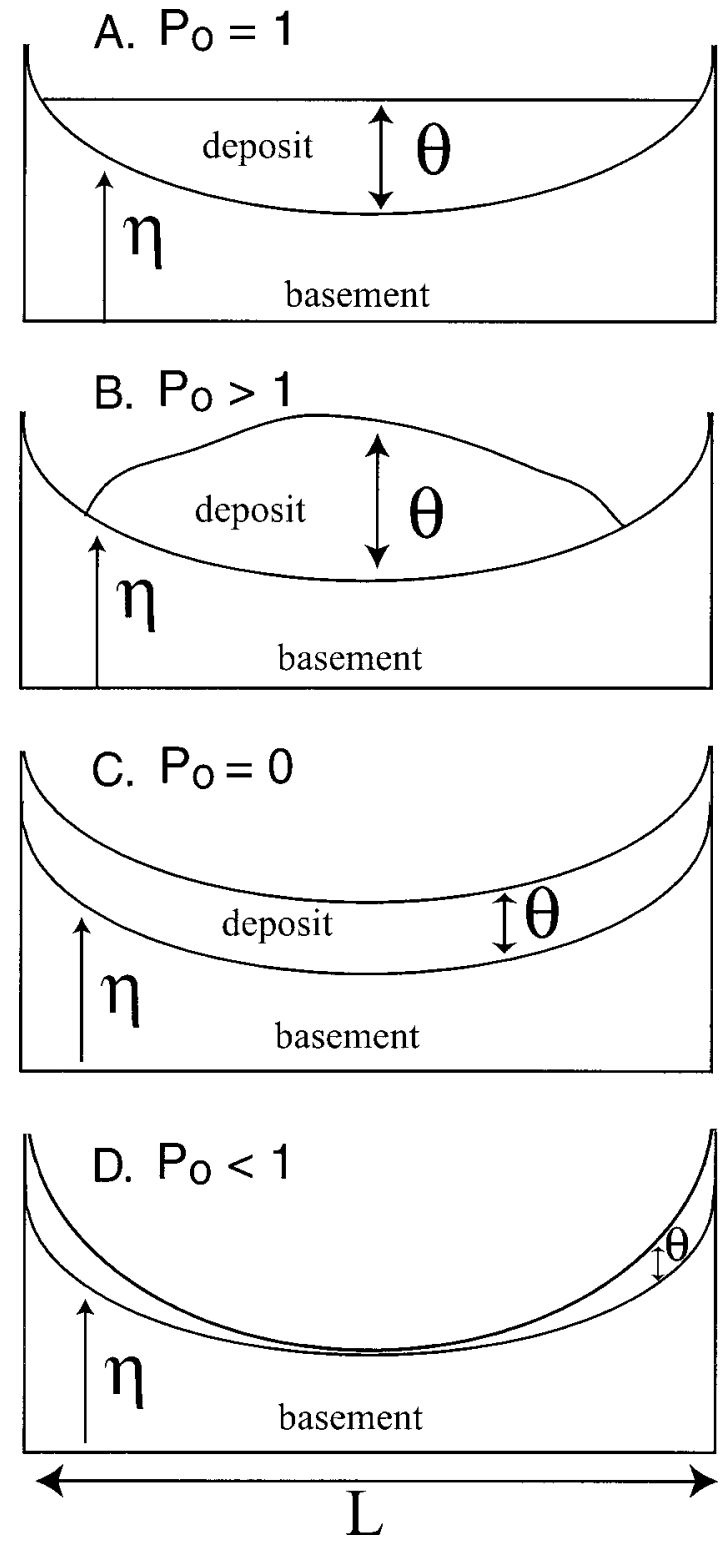

FIG. 4.-Four regimes of deposition described by the deposit ponding index are A) a perfectly ponded deposit: Po $=1, \mathbf{B})$ a mounded deposit: Po $>1, \mathbf{C})$ a perfectly draped deposit: Po $=0$, and $\mathbf{D})$ a deposit with accentuated highs: Po $<$ 0. drowned inlet, and again resulting in a quasi-steady, highly subcritical turbidity current (Fig. 5). Owing to the presence of the drowned inlet, each of these runs can be interpreted in terms of an equivalent run with supercritical flow and a hydraulic jump to highly subcritical flow specified farther upstream of the headgate.

In the experiments the damming effect was strong enough to produce a dammed turbidity current, i.e., a current that because of an obstruction is very deep, very slow-flowing, and has a very low densimetric Froude number. This flow damming was manifested in the nonturbulent, glassy interface between the turbid water and the clear water above in Figure $3 \mathrm{~B}$, evidencing very slow, subcritical flow. In the zone of dammed flow, the interface between turbid water and clear water above was horizontal from either the downstream side of the jump (experiment $\mathrm{c} 3$ ) or the headgate (experiments $\mathrm{c} 1, \mathrm{c} 2$, and $\mathrm{c} 4$ ) to a point near the basin lip, beyond which it dropped downward as the current flowed over the downstream basin lip (Fig. 3B). This is in strong contrast to the head of the turbidity current of Figure 3A before setup was complete, which showed strong turbulent deformation. It should be noted that the continuous turbidity currents in these experiments still overflowed the downstream lip of the basin, i.e., the flows were partially rather than fully dammed. Although the experimental basin was never completely filled with sediment, damming of the turbidity current would likely have persisted until the basin was nearly full of sediment, so that the lip no longer presented an obstacle.

The turbidity-current deposits, or turbidites, resulting from the continuous flows had a drape-like geometry as shown in Figure 6. The deposits had a deposit ponding index ranging from 0.11 to 0.37 , indicating a deposit closer to a draped deposit than a ponded deposit (Table 1). The deposit ponding index varied inversely with the input flow rate for runs $\mathrm{c1}, \mathrm{c} 2$, and $\mathrm{c} 4$, indicating that higher discharges led to more draped deposits. Run c3, however, did not follow this trend.

Three distinct depositional zones are recognizable in Figure 6. A proximal zone extends from the headgate to about $1.25 \mathrm{~m}$ downstream. In this zone the bed has a slope of about 0.084 , or a slope angle of about $4.8^{\circ}$. Beyond this is a basin zone extending from $1.25 \mathrm{~m}$ to $3.5 \mathrm{~m}$, over which the average bed slope is 0.0022 and the slope angle is $0.012^{\circ}$. Beyond this is the zone of the basin lip, over which the bed rises by $12.7 \mathrm{~cm}$ over a length of $0.5 \mathrm{~m}$.

Each of the deposits from runs $\mathrm{c} 1-\mathrm{c} 3$, which used a slurry composed of kaolinite and $20 \mu \mathrm{m}$ silt, had a nearly constant thickness in the proximal zone and in the corresponding basin zone, as shown in Figure 6. In the case of run c4, which used kaolinite and $45 \mu \mathrm{m}$ silt, the proximal deposit formed a wedge tapering down to the deposit thickness in the basin zone. This tapering of deposit thickness in the streamwise direction occurred even in the basin zone. Evidently the coarser sediment tended to deposit preferentially in the proximal zone. In all cases very little deposition occurred in the lip zone.

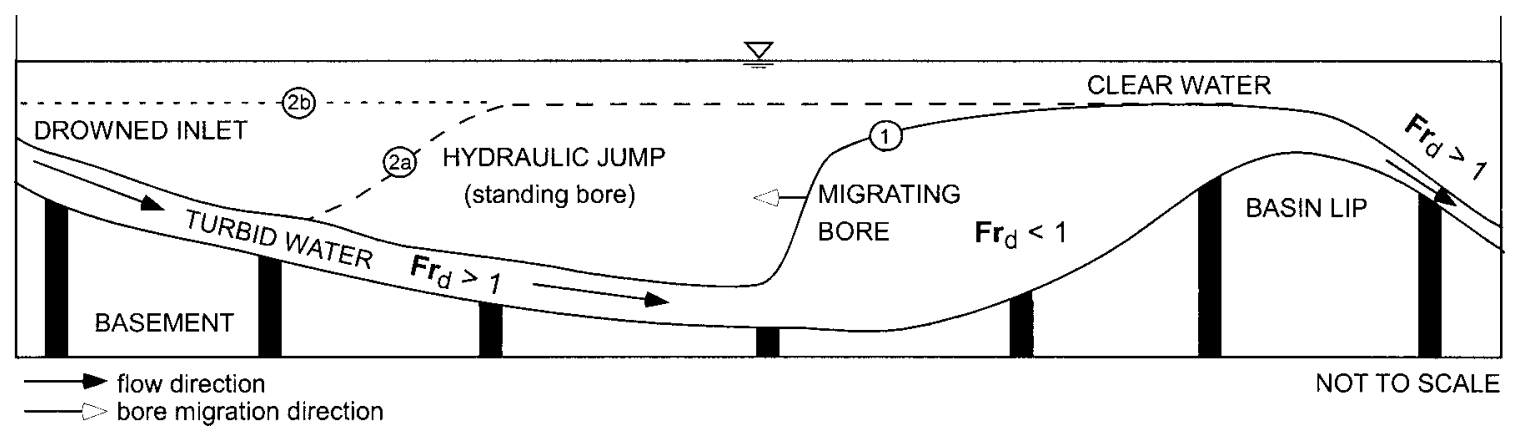

FIG. 5.-Schematic diagram of a continuous turbidity current flowing into the experimental flume after the flow reached the basin lip but before setup was complete (solid line) and after setup of a dammed turbidity current (dashed lines). Note the upstream migrating bore (line 1), which eventually stabilized within the first 80 seconds of each continuous-feed experiment into either a quasi-steady hydraulic jump for the case of experiment $\mathrm{c} 3$ (line $2 \mathrm{a}$ ) or a drowned inlet for the case of experiments c1, $\mathrm{c} 2$, and $\mathrm{c} 4$ (line 2b). 


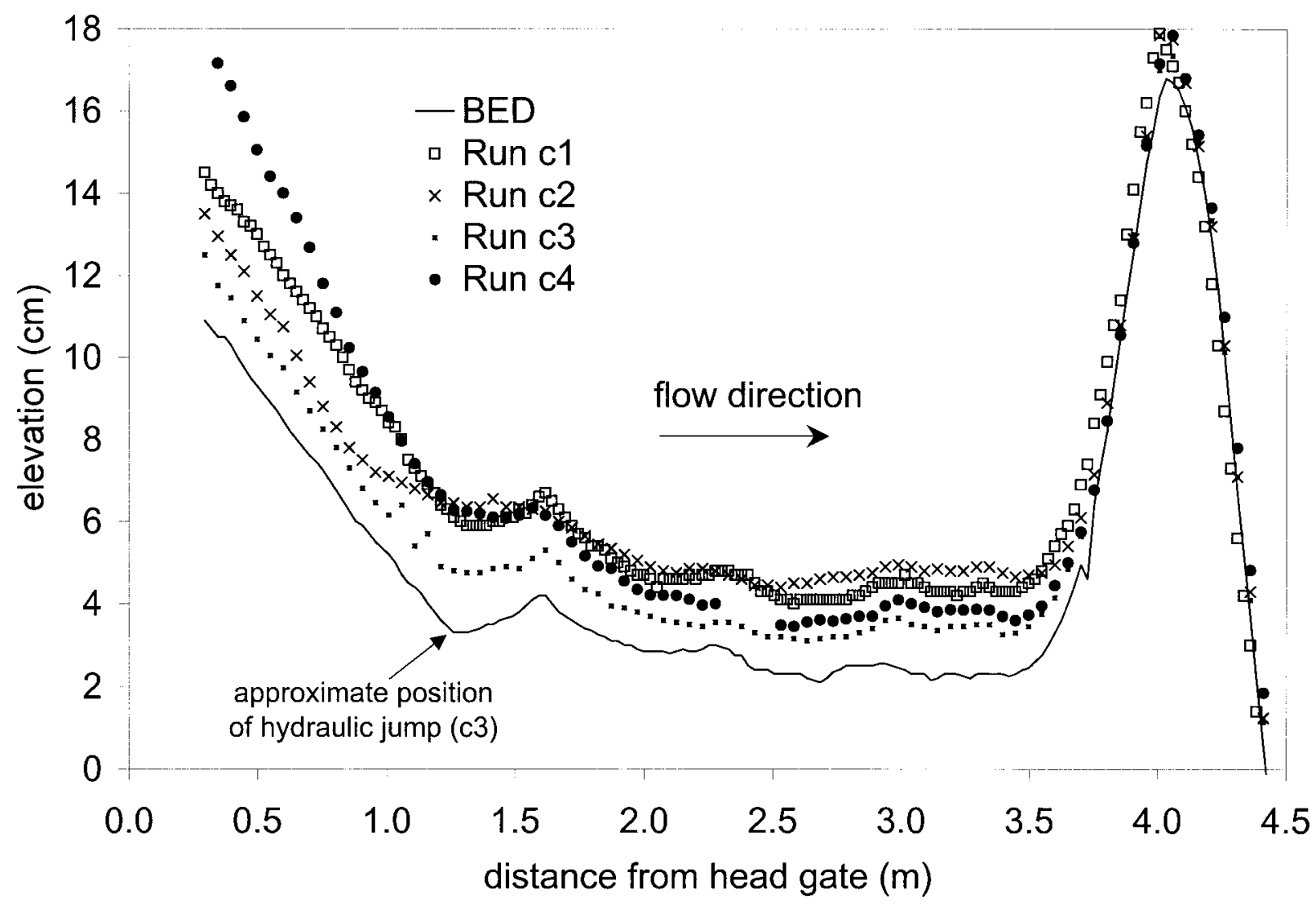

FIg. 6. - Graph of the final deposit elevation for the four continuous-feed runs (c1-c4). Runs c1, c2, and c3 had a $20 \mu \mathrm{m}$ silt fraction and c4 had a $45 \mu \mathrm{m}$ silt fraction. The slurry input flow rate was $0.85 \mathrm{l} / \mathrm{s}, 0.5 \mathrm{l} / \mathrm{s}, 2 \mathrm{l} / \mathrm{s}$ and $1 \mathrm{l} / \mathrm{s}$, for $\mathrm{c} 1-\mathrm{c} 4$, respectively. The deposits for all of the continuous turbidity currents had deposit ponding indices most representative of a drape.

For the continuous flows presented here, the glassy interface between sediment-laden water and clear water stabilized at an elevation above the downstream lip of the basin after setup of dammed flow was complete, as can be seen in Figure 3B. This led to significant basin overflow and inefficient trapping of sediment within the basin. The trapping efficiency of the minibasin is here defined as the ratio of the sediment deposited in the basin during the experiment to the total sediment fed in during the same experiment. As shown in Table 1, runs c1, c2, and c3 had approximately equal trapping efficiencies of $15 \%$, in spite of the fact that inflow slurry discharge took the corresponding values $0.5,0.85$, and $2.0 \mathrm{l} / \mathrm{s}$. The inflow slurry in all these runs consisted of $20 \mu \mathrm{m}$ silt and kaolinite clay. Run $\mathrm{c} 4$, on the other hand, had a trapping efficiency of $32 \%$; the inflow slurry discharge was $1 \mathrm{l} / \mathrm{s}$ and the sediment consisted of $45 \mu \mathrm{m}$ silt and kaolinite clay. Evidently grain size exerts a much stronger control on trapping efficiency than does flow discharge in these experiments.

\section{Surging Turbidity Currents}

The surging flows had turbulent heads that were identical to those of the continuous flows. However, the cessation of slurry input after 15 seconds caused the surging turbidity currents to have discrete, small bodies in comparison with the continuous turbidity currents. The surges were chosen to be small enough (approximately 10\% of the basin capacity) to prevent much overflow from the basin. As a result, the turbidity-current head approached the lip, climbed up it, and then reflected backward with little spillover. The surging flows did not undergo a hydraulic jump because the input discharge was turned on for only 15 seconds, a time insufficient for setup of quasi-steady flow with a hydraulic jump. Repeated reflection from one end of the basin to the other again led to the formation of a muddy pond in the basin, but this time with almost no overflow. The muddy pond was allowed to settle out for approximately eight hours before the next surge event.

An ultrasonic sonar system was used to measure the bed elevation between surges. Vertical stacking of these profiles led to the generation of the reconstructed depositional record shown in Figure 7, which characterized the stratigraphic architecture of the basin fill. Each of the deposits from the twelve surge events formed a thin, normally graded bed, characterized by a cap of slightly darker fine sediment (Fig. 8).

The final deposit, consisting of twelve stacked turbidites, each resulting from an individual surging turbidity current, was notably more ponded than the deposits from the continuous turbidity currents (Table 1). Most of the individual surge deposits were slightly ponded (Fig. 9), with an average ponding index for the individual surge deposits of 0.11 . This resulted in a ponding index very close to zero for the cumulative surge deposit after the first few surges, indicating a draped deposit. However, the addition of each slightly ponded surge deposit resulted in a cumulative deposit that became more ponded with each successive surge, reaching a value of 0.57 after the last surge event (s12). Therefore, the ponding index of the cumulative surge deposit varied directly with the surge number.

The proximal deposits of the surge-feed turbidity currents tended to be very thin relative to the deposits in the basin zone (Fig. 7), in contrast to those of the continuous runs (Fig. 6). The surging flows had very short bodies (in length or duration), and thus were dominated by the turbulent head of the turbidity current. In contrast, the continuous flows had long bodies, and therefore were dominated by the less turbulent body of the turbidity current. The implication is that within this proximal region the heads of the turbidity currents were more competent and thus kept more sediment in suspension than the bodies of the turbidity currents. 


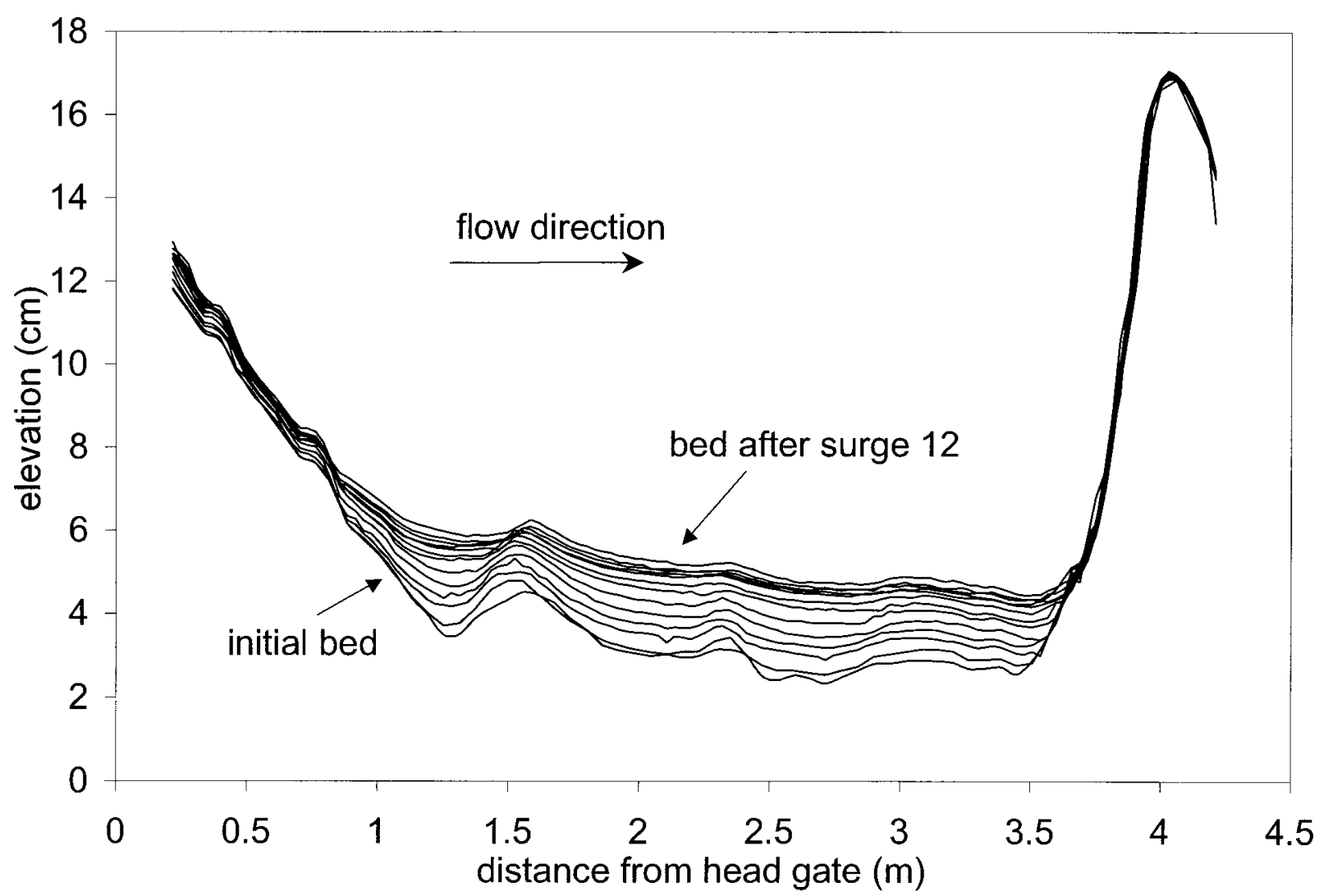

FIG. 7.-Sonar profiles of each surge deposit, twelve of which were stacked on top of one another. In contrast to the deposits for the continuous experiments, the surging turbidity currents left a deposit that became more ponded with successive stacking of events.

The trend toward a more ponded cumulative deposit with successive surges corresponded with the observation that successive surges had lower average head velocities, as shown in Figure 9. The velocities of the surges were calculated by visually measuring the time it took for the head of the turbidity current to traverse the middle portion of the minibasin. The head of the initial surges traveled with an average velocity near $12 \mathrm{~cm} / \mathrm{s}$. Later surges, however, had average velocities near $9 \mathrm{~cm} / \mathrm{s}$.

The relationship between the average head velocity of a turbidity current and the ponding index of the cumulative deposit can be explained in terms of feedback. If the deposit had been a perfect drape $(\mathrm{Po}=0)$, then the head velocities of the surges should not have changed, because the slope of the sediment bed would not have changed with time. However, the deposit from the surge-feed turbidity currents, after the second surge (s2), had a geometry that was between purely draped and purely ponded $(0<$

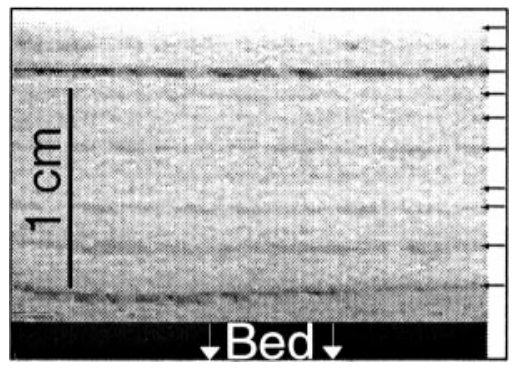

FIG. 8.-A close-up photograph of the final cumulative deposit from the experiment on surging turbidity currents. The individual surge deposits can be distinguished by their caps of fine particles visualized as slightly darker lines in the deposit. Black arrows on the photograph highlight these fine caps.
Po $\leq 1)$. Therefore, the center of the minibasin filled faster than the updip and downdip ends of the minibasin (Fig. 7), thus reducing the overall incoming slope of the sediment bed and reducing the velocity of each successive turbidity current head.

In contrast to the continuous-feed turbidity currents, the surge-feed tur-

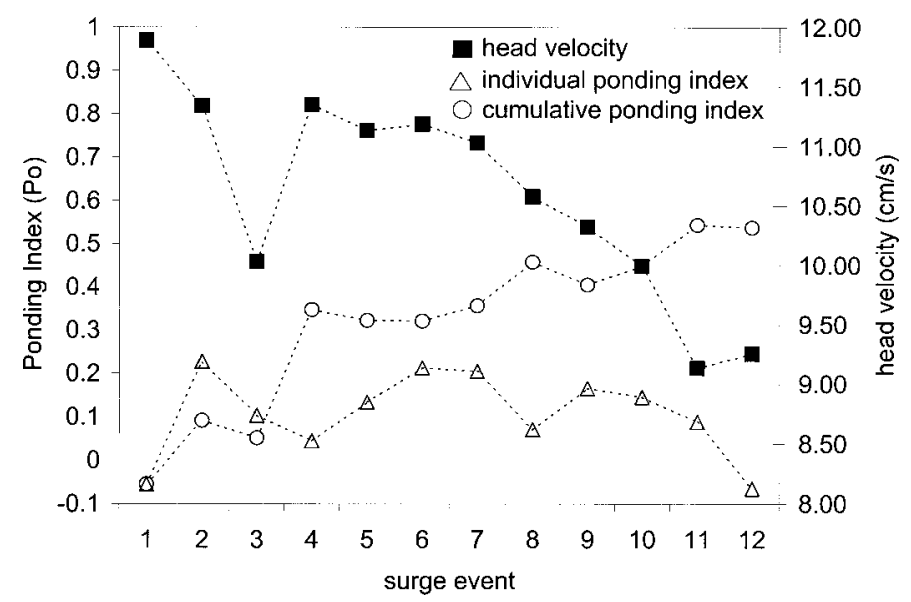

FIG. 9.-Graph showing the deposit ponding index of the individual surge turbidites (triangles), the deposit ponding index of the cumulative surge deposit (circles), and the average head velocity for each surging turbidity current (squares), with surge event \# 1 being the first surge. The individual surge deposits were slightly ponded, with an average ponding index of 0.11 . The cumulative surge deposit was initially draped $(\mathrm{Po} \rightarrow 0$ ) but moved toward a more ponded form $(\mathrm{Po} \rightarrow 1)$ with each successive surge. The trend toward a more cumulative ponded deposit corresponded with slower average head velocities of successive surge flows. 
bidity currents were almost completely captured in the minibasin. The experimental minibasin had a trapping efficiency of $99 \%$ for the surge-feed turbidity currents (Table 1). Only the very front a surge was able to overflow the downstream lip of the basin.

\section{DISCUSSION}

\section{Setup Time for a Continuous Turbidity Current}

The difference between continuous and surging turbidity currents can be defined in terms of the setup time for the establishment of quasi-steady dammed flow with either an internal hydraulic jump or a drowned inlet. The process of setup requires the head of the turbidity current to reach the downstream lip of the basin, to then partially reflect off of it to form an upstream-migrating bore, and then for the bore to stabilize as an internal hydraulic jump. The experiments indicated that the flow must be sustained for about 30-50 seconds beyond the time when the turbidity current head reached the downstream basin lip in order for full setup of a quasi-steady dammed flow. A current that persists for much longer than this can be described unambiguously as continuous, as was the case for runs c1-c4. A current much shorter than this can be described unambiguously as surging, as was the case for runs $\mathrm{s} 1-\mathrm{s} 12$.

It is useful to have a scale estimate for setup time in order to compare the experiments with a natural system. Here this is crudely quantified in terms of the time required for the upstream-migrating bore to migrate a distance $L_{p}$ from the basin lip to the transition point between the proximal and basin zones, where the hydraulic jump was generally located. The shallow-water wave speed $c$ for an upstream-migrating internal bore is

$$
c \approx \sqrt{\operatorname{Rg} C_{p} \Delta h}
$$

where $C_{p}$ denotes the volume concentration of suspended sediment in the dammed zone and $\Delta h$ denotes the height of the bore (e.g., Turner 1973). The time $T_{b}$ for the bore to migrate upstream a distance $L_{p}$ is thus scaled as

$$
T_{b} \approx \frac{L_{p}}{c}=\frac{L_{p}}{\sqrt{R g C_{p} \Delta h}} .
$$

In our experiments, $L_{p}$ is estimated as $3 \mathrm{~m}, \Delta h$ is estimated as half the basin relief, or about $0.06 \mathrm{~m}, R$ is set equal to 1.65 (quartz silt) and $C_{p}$ is estimated as 0.01 , on the basis of unpublished data on sediment concentration from similar experiments in the same flume. This results in an estimate for $T_{b}$ of about 30 seconds, a value that is similar to observed values. Equation 4 allows estimates at field scale. Consider a case for which $L_{p}=$ $10,000 \mathrm{~m}, \Delta h=100 \mathrm{~m}, R=1.65$, and $C_{p}=0.01$, which are reasonable basin dimensions for many minibasins in nature (e.g., Winker 1996; Beauboeuf and Friedman 2000). The computed estimate of $T_{b}$ is 41 minutes. That is, the time required for the bore to migrate to the upstream end of the basin is on the order of 41 minutes. Flows with a duration significantly shorter than this likely cannot set up a sustained quasi-steady flow in the hypothetical basin, and thus would be classified as surges.

The above calculation suggests that a turbidity current must be sustained for at least on the order of an hour in order to set up a continuous flow in a natural system. There are at least two processes by which such sustained turbidity currents can form. The first of these is a hyperpycnal river flood flow, which forms when the river water is so laden with sediment that it is denser than seawater, so that it plunges to the ocean floor at the river mouth to form a continuous turbidity current (Mulder and Syvitski 1995). The second of these is ignition, by which a relatively small turbidity current generated in situ can, under the right conditions, entrain sediment, selfaccelerate, and grow. Parker et al. (1986) demonstrated the conditions under which a continuous turbidity current can self-accelerate downslope. Pratson et al. (2000) showed how the same process can convert a relatively small, surge-like turbidity current into a much more sustained event.

\section{Surging and Continuous Flow Deposits}

The ponded geometry of the cumulative surge deposit is shown in Figure 7. Note that the cumulative surge deposit was thickest in the center of the basin. A few tens of seconds after the head of a surge-feed turbidity current reached the lip of the basin and was reflected back into the basin, the sediment began to settle passively, because little turbulent energy was available to maintain suspension. At this point, a horizontal settling interface formed between the turbid pond and the sediment-free water above and migrated downward at the rate of particle settling until nearly all of the sediment was deposited. Because of the concavity of the long profile of the basin and the horizontal settling interface, more sediment was deposited near the center of the basin for each surge event, leading to a successively more ponded cumulative deposit.

In contrast, the interface between turbid and clear water, or the settling interface, was steady for the continuous-feed experiments, bounded upstream by either a quasi-steady hydraulic jump or the headgate and downstream by the lip of the basin. For the surging runs most of the sediment was deposited during the settling period, after the flow was turned off, resulting in a ponded deposit. For the continuous flows, most of the sediment was deposited during the experiment, while the flow was still entering the basin and while the settling interface was steady. This led to approximately equal deposition in the streamwise dimension of the basin and therefore a drape-like deposit in the basin zone. In nature, if the duration of the flow is long enough to set up a dammed flow, a draped deposit also should result.

Grain-size measurements of the turbidity currents and their deposits were not taken for these experiments. However, it is speculated from visual estimates that the surging deposits were overall finer grained than the continuous flow deposits because a significant amount of sediment overflowed the basin during the continuous flows. Turbidity currents that are entirely captured within a basin can sort the sediment only in the vertical direction. If there is escape, however, the finer material is more likely to escape, so that coarser material concentrates in the basin. A detailed analysis of sediment concentration and grain size of dammed turbidity currents and their associated deposits is the subject of future experiments.

The continuous-feed deposits shown in Figure 6 indicate substantial deposition in the proximal zone. As shown in the "Fan Lobes" unit of Figure 1, proximal deposition can occur in natural minibasins during some stages of deposition. However, in nature this proximal zone often, but not always, includes a channel incised into the ridge bounding the minibasin (Liu and Bryant 2000). A small-scale model is not an exact replica of nature, and the minibasin described here is orders of magnitude smaller than its natural counterparts. Sediment size, however, cannot be scaled down by a commensurate amount. The addition of kaolinite clay to the experimental currents was intended to compensate at least partially for this drawback. However, erosion is difficult to model in the laboratory at reduced scale. Therefore, the proximal deposition observed in the continuous-feed experiments may not be representative of some natural minibasins.

\section{Limiting Size of a Surge Deposit}

We found that for nearly all of the sediment to be captured, the volume of a surge must not exceed approximately $10 \%$ of the capacity of the experimental basin. The " $10 \%$ rule" is probably not representative of fieldscale processes, because the likelihood of surge capture depends on basin geometry. For example, a surge has a better chance of escaping a shorter basin than a longer basin, because there is less distance over which friction slows down the surge advance.

However, from the timescale for setup calculated above, it is possible to estimate the largest volume of flow, with respect to basin capacity, that still behaves like a surging turbidity current. It was found that the maximum duration of a flow in nature must be less than on the order of an hour for 
surge-like behavior. Therefore, the maximum volume of a surging turbidity current is estimated as $0.25 \mathrm{~km}^{3}$ by assuming a flow duration of 1 hour and a discharge of $70,000 \mathrm{~m}^{3} / \mathrm{s}$, which is the highest recorded discharge of the Mississippi River (Barry 1997). This flow is likely an upper bound for surge-like behavior, because 1 hour is within the transition to continuous flow and turbidity currents are probably not much larger than the size of the largest flood of the Mississippi River. In addition, a turbidity current sourced from the Mississippi River would likely grow in size because of water entrainment and/or ignition (Parker et al. 1986). A surging turbidity current with a total volume of $0.25 \mathrm{~km}^{3}$ would fill a typical minibasin, with a basin capacity of $25 \mathrm{~km}^{3}, 1 \%$ full of slurry. This puts an upper limit on the size of surge deposits when the concentration of the flow and the porosity of the bed can be estimated. Assuming a volumetric sediment concentration of $1 \%$ and a bed porosity of $50 \%$, the deposit from this hypothetical flow would fill $0.02 \%$ of the basin with sediment.

\section{CONCLUSIONS}

We report on laboratory experiments on the dynamics and deposits of both continuous and surging turbidity currents flowing into a model intraslope minibasin. The continuous flows were designed to allow for substantial overspill from the basin. The sediment trapping efficiency of the basin depended more strongly on grain size than flow discharge for the continuous flows. The surging flows were designed to allow nearly complete capture of the sediment within the basin. Continuous-feed and surgefeed turbidity currents were found to leave distinct signatures in their deposits, as characterized by a dimensionless ponding number (Po); the former are more draped, and the latter develop strong ponding as deposits stack.

The differences between the deposits of continuous and surging turbidity currents are likely due to the relative proportion of head to body of the flows. The continuous flows quickly led to the setup of a quasi-steady dammed turbidity current, bounded on the upstream end by either an internal hydraulic jump or the headgate and on the downstream end by the lip of the basin. This resulted in approximately constant deposition in the streamwise direction of the basin zone, and therefore, a draped deposit. The surging turbidity currents were shorter than the continuous turbidity currents and therefore had more of their total sediment load in the turbulent head of the turbidity current, which allowed the flow to carry sediment farther from the source. The surges were small enough, however, to prevent escape from the basin. The surging flows resulted in a ponded deposit due to the concavity of the basin.

When the duration of a flow is much less than the time needed for setup of a quasi-steady dammed turbidity current, the flow can be defined as a surge. On the other hand, if the duration of a flow is significantly longer than time needed for setup, the flow can be described as continuous. For natural-scale minibasins, this timescale is estimated to be on the order of an hour. This puts an approximate limit on the size of surging flows. Using this timescale, the ponded deposits from surging flows in the field should have a small volume compared to the basin capacity. The trapping efficiencies of large continuous flows are less than those of surging flows, but the duration of continuous flows can be much longer, resulting in the possibility for greater basin deposition.

\section{ACKNOWLEDGMENTS}

We thank Richard Hiscott, Mary Kraus, Paul Myrow, Carlos Pirmez, and John Southard for comprehensive reviews that greatly improved this paper. This research was supported by the St. Anthony Falls Oil Consortium (ExxonMobil, CevronTexaco, ConocoPhillips, and Japan National Oil Company) and the Office of Naval Research STRATAFORM program.

\section{REFERENCES}

BarRy, J.M., 1997, Rising Tide: New York, Simon and Schuster, 574 p.

Beauboeuf, R.T., and Friedman, S.J., 2000, High resolution seismic/sequence stratigraphic framework for the evolution of Pleistocene intra slope basins, western Gulf of Mexico: depositional models and reservoir analogs: Gulf Coast Section, Society of Economic Paleontologists and Mineralogists, 20th Annual Research Conference, Deep-Water Reservoirs of the World, Dec. 3-6, p. 40-60.

Brami, T.R., Pirmez, C., Archie, C., and Holman, K.L, 2000, Late Pleistocene deep-water stratigraphy and depositional processes, offshore Trinidad and Tobago: Gulf Coast Section, Society of Economic Paleontologists and Mineralogists, 20th Annual Research Conference, Deep-Water Reservoirs of the World, Dec. 3-6, p. 104-115.

Divins, D.L., 2001, Coastal Relief Model: http://www.ngdc.noaa.gov/mgg/coastal.

GarCÍA, M.H., 1993, Hydraulic jumps in sediment-driven bottom currents: Journal of Hydraulic Engineering, v. 119, p. 1-24.

García, M.H., and Parker, G., 1989, Experiments on hydraulic jumps in turbidity currents near a canyon-fan transition: Science, v. 28, p. 393-396.

Hickson, T., SheEts, B., AND MARR, J., 2000, Filling of intraslope basins by turbidity currents: results from experimental simulations (abstract): American Association of Petroleum Geologists, Annual Convention, April 16-19, Abstracts.

Liu, J.Y., AND BRYANT, W.R., 2000, Sea floor morphology and sediment paths of the northern Gulf of Mexico deepwater, in Bouma, A.H., and Stone, C.G., eds., Fine-Grained Turbidite Systems: American Association of Petroleum Geologists, Memoir 72; SEPM, Special Publication 68, p. 33-45.

Mulder, T., AND Syvitski, J.P.M., 1995, Turbidity currents generated at river mouths during exceptional discharges to the world oceans: Journal of Geology, v. 103, p. 285-299.

Parker, G., Fukushima, Y., and Pantin, H.M., 1986, Self-accelerating turbidity currents: Journal of Fluid Mechanics, v. 171, p. 145-181.

Pratson, L.F., and Ryan, W.B.F., 1994, Pliocene to Recent infilling and subsidence of intraslope basins offshore Louisiana: American Association of Petroleum Geologists, Bulletin, v. 78, p. 1483-1506.

Pratson, L.F., Imran, J., Parker, G., Syvitski, J.P.M., and Hutton, E., 2000, Debris flows versus turbidity currents: a modeling comparison of their dynamics and deposits, in Bouma A.H., and Stone C.G., eds., Fine-Grained Turbidite Systems: AAPG, Memoir 72; SEPM, Special Publication 68, p. 57-72.

Salaheldin, T.M., Imran, J., Chaudhry, M.H., and Reed, C., 2000, Role of fine sediments in turbidity current flow dynamics and resulting deposits: Marine Geology, v. 171, p. 21-38.

Schollnberger, E., and Vail, P.R., 1999, Seismic sequence stratigraphy of the lower Congo, Kwanza, and Benguela basins, offshore Angola, Africa: American Association of Petroleum Geologists, Bulletin, v. 83, p. 1338.

TuRnER, J.S., 1973, Buoyancy Effects in Fluids: Cambridge, U.K., Cambridge University Press, $367 \mathrm{p}$.

WINKER, C.D., 1996, High-resolution seismic stratigraphy of a late Pleistocene submarine fan ponded by salt-withdrawal mini-basins on the Gulf of Mexico continental slope: 28th Annual Offshore Technology Conference, Proceedings, p. 619-628.

Received 15 January 2003; accepted 21 June 2003 